\title{
QUALITY OF LIFE QUESTIONNAIRE FOR CHILDREN WITH CEREBRAL PALSY (CP QOL-CHILD): TRANSLATION AND CULTURAL ADAPTATION TO THE BRAZILIAN PORTUGUESE LANGUAGE
}

\author{
Lígia Maria Presumido Braccialli ${ }^{1}$, Ana Carla Braccialli², Andréia Naomi Sankako ${ }^{3}$, \\ Maria Luiza da Costa Dechandt ${ }^{4}$, Vanessa da Silva Almeida5, \\ Sebastião Marcos Ribeiro de Carvalho ${ }^{6}$
}

\begin{abstract}
The aim of this study was to verify the reliability of the Brazilian Portuguese version of the instrument Cerebral Palsy: quality of life questionnaire for children: primary caregiver questionnaire (CP QOLChild: primary caregiver) translated and culturally adapted. Thus, the translation and cultural adaptation of the instrument was made, and then the procedures to verify its reliability were performed. The translated and culturally adapted questionnaire was answered by 30 caregivers of children with cerebral palsy and inter- and intra-observer analysis followed. The data allowed the authors to identify an internal consistency rangering from 0.649 to 0.858 , intra-observer reliability from 0.625 to 0.809 and inter-observer reliability from 0.498 to 0.903 . The analysis suggests that the instrument has acceptable psychometry.
\end{abstract}

Key words: quality of Life; cerebral palsy; assessment instrument.

\section{INTRODUCTION}

Cerebral Palsy (CP) is the most common cause of motor disability in childhood ${ }^{1-3}$ in developed countries with an incidence ratio of 2-2.5/1000 live births $4,5,6$. In Brazil the ratio is estimated at 7 per 1000 live births ${ }^{7}$. The prevalence of CP in Europe in the period between 1976 and 1990, was of 2.08 per 1000 live births ${ }^{8}$.

$\mathrm{CP}$ is characterized by mobility and posture disorders that cause limitations in activity, attributed to non-progressive alterations that occur in the fetal or infant brain. The motor disorders are often accompanied by sensory and cognitive, communication, perception, behavioral alterations and/or seizures ${ }^{9}$. For the authors mentioned above, some manifestations associated with $\mathrm{CP}$ may prove more significant in some individuals or in some periods, while other manifestations may be more apparent or more problematic at different stages of a child's life.

Despite medical treatment and rehabilitation, several motor limitations may reduce functionality, motor skills ${ }^{10}$, health ${ }^{11}$ and the quality of life ${ }^{12}$ of these children.
In order to check the impact of therapy on functionality and motor performance of children with $\mathrm{CP}$, there has been a concern in develop to standardized instruments that contain appropriate and objective measures of what it is intended to assess ${ }^{13}$.

The assessment measures that have been used include evaluation scales of spasticity, gross and fine motor skills tests that assess alteration in function, and gait analysis to demonstrate standard alterations ${ }^{14}$. More recently, the need to acknowledge the pathological effects on the health and well-being from the perception of the individual or of his/her caregiver has resulted in consultless of efforts to develop instruments to assess the impact on these children's quality of life $(\mathrm{QOL})^{15}$.

A study developed by Wallander, Schmitt and Koot $^{16}$ ascertained that of 20,000 articles on quality of life published between 1980 and 1994, only 13\% made any reference to children, and the least studied was the age group between 6 and 12 years old.

Assessing QOL of children has been a challenge, since they typically have been regarded as unreliable respondents. However, there is increasing evidence that children can carry out selfreport QOL reliably if their emotional development,

\footnotetext{
1 Docente do Departamento de Educação Especial da Faculdade de Filosofia e Ciências, Unesp de Marília - bracci@marilia.unesp.br

2 Fisioterapeuta da AACD - Rio Preto, São José do Rio Preto.

3 Doutora em Educação -Faculdade de Filosofia e Ciências, Unesp de Marília.

4 Fisioterapeuta - Faculdade de Filosofia e Ciências, Unesp de Marília.

5 Bolsista FUNDAP do Programa de Aprimoramento em Fisioterapia na Faculdade de Filosofia e Ciências, Unesp de Marília.

6 Docente do Departamento de Psicologia da Educação da Faculdade de Filosofia e Ciência, Unesp de Marília. Corresponding Author: bracci@marilia.unesp.br
}

Suggested citation: Braccialli LMP, et al. Quality of life questionnaire for children with cerebral palsy (CP QOL-CHILD): translation and cultural adaptation to the Brazilian Portuguese Language; Journal of Human Growth and Development 2013; 23(2): 157-163 Manuscript submitted Feb 01 2012, accepted for publication Dec 192012. 
cognitive abilities and reading level are taken into account ${ }^{17}$.

The limitations in existing instruments that measure QOL in children, have stimulated the development of a specific QOL scale for children with cerebral paralsy ${ }^{18}$. To be able to measure quality of life of children with $\mathrm{CP}$, however, it is important to overcome several methodological obstacles, especially those related to communication barriers and the wide range of impairment in this population as well as the lack of specific validated instruments ${ }^{19}$.

A specific instrument to measure quality of life of children with CP must address the feelings regarding the adapted equipment used and feelings regarding doctors or therapeutic and surgical interventions ${ }^{10}$, level of satisfaction in access to services, assistive technology resources availability and acceptance within their community ${ }^{14}$. These issues are beyond the scope of a generic instrument, and thus omit potentially important opinions in relation to some aspects of these individuals' daily lives.

The World Health Organization (WHO) recommends that QOL assessments in children, whenever possible, be done through self-reporting. It has been shown that children, even the smallest ones, are capable of self-reporting. However, there is concern that due to developmental problems, young age, severity of illness or disability and cognitive deficit, reports may be unreliable. When children cannot perform self-reporting, quality of life assessment can be carried out by their parents, as it is believed that they have a thorough understanding of their children and are able to provide real information about them. It is now widely recognized that both self-reporting and reports of caregivers provide important additional information regarding the children's $\mathrm{QOL}^{20}$.

Viehweger et al. ${ }^{12}$ reported the importance of supplementing the self-assessment of the child with CP with the caregiver's assessment due to possible cognitive impairment present in some cases, although the nature of the information collected is different.

Currently, the need for a specific, valid and reliable instrument for assessing the well-being of children with CP is clear. The Cerebral Palsy: Quality of Life Questionnaire for Children (CP QOL-CHILD) was developed to assess the well-being rather than the malaise of these children. Three important aspects regarding the design of the questionnaire should be highlighted: (1) it is based on the Classification of Functioning and Disability (CFD), (2) it was developed by international specialists, and (3) it recognizes the importance of the childrens' and their caregivers' perceptions. The questionnaire exists in two versions: the first version CPQOL-Child Primary Caregiver Questionnaire (4-12 years) and the second version CPQOL-Child Child Report Questionnaire (9-12 years). The form filled in by the caregivers can be used for children from 4 years old to ensure clear diagnosis of CP. Children older than 12 years were not included, as it would be necessary to include new issues such as body image, sexuality, pressure from school and jobs that arise during adolescence ${ }^{14}$.

The version CP QOL-Child Primary Caregiver Questionnaire (4-12 years) has 66 questions and should be answered by the parents/caregivers of children with cerebral palsy, who report their perception of their child's quality of life by areas: well-being and social acceptance, functionality, participation and physical health, emotional wellbeing and self-esteem, access to services, pain and disability impact and family health.

The version CP QOL-Child Child Report Questionnaire (9-12 years) presents 53 questions divided by areas: well-being and social acceptance, functionality, participation and physical health, emotional well-being and self-esteem, access to services and pain and impact disability. This version should be answered by the children with $C P$, that is, it is the child's self-report ${ }^{21}$.

Providing a standardized and validated instrument for Brazilian Portuguese will make it possible to measure the quality of life of children with cerebral palsy and will serve as a parameter to check how effectively public policies in education and health contribute to the well being of this population. In relation to education, it will make it possible to verify which domains of quality of life are influenced when school inclusion is provided for students with cerebral palsy. Such an instrument can also verify the effectiveness of the therapeutic and preventive actions developed and used with this population.

In this perspective, this study aims to determine the reliability of the Brazilian Portuguese version of the instrument Cerebral Palsy: quality of life questionnaire for children: primary caregiver questionnaire (CP QOL-Child: primary caregiver) translated and culturally adapted.

\section{METHOD}

Firstly, the authorization or the part of the authors of the CP QOL-Child at the School of Health and Social Development of Deakin University (Victoria, Australia) to perform the translation, cultural adaptation and validation for the Portuguese language was requested.

After the approval granted by the authors, the project was referred to the Ethics Committee in Research for analysis, obtaining positive consent under the number 278/2009.

\section{Participants}

In this phase of the study 30 caregivers of children with cerebral palsy, male and female, with a mean age of $34.3 \pm 10.7$ years old participated. The inclusion criteria for the study participants were: parents or primary caregivers of children with 
cerebral palsy aged 4-12 years. Children's parents or legal guardians who agreed to participate in the study signed an informed consent.

\section{Procedures}

The original English version of the CP QOLCHILD was first translated and culturally adapted into Brazilian Portuguese. The process of translation and cultural adaptation followed international recommendations ${ }^{21-24}$.

Thus, some steps have been met: 1) translation into Brazilian Portuguese; 2) compromised translation; 3) back translation 4); final translation; 5) pretest; 6) cultural adaptation $^{21}$.

At first, two translators independently translated the CP QOL-Child from English to Brazilian Portuguese. Both met as requirement: 1) knowledge of English and Portuguese, and 2) Brazilian Portuguese as their native language. The following guidelines were given to the translators: (1) use natural and language acceptable to the wider public, 2) perform a clear, simple and understandable translation, 3) avoid long, complex sentences 4) always focus on conceptual equivalence instead of literal translation; 5) consider the age of the respondents to the questionnaire, as well as how well they will understand these items; 6) avoid using slang or difficult terminology; 7) avoid double negatives ${ }^{25}$.

In the second step, compromised translation, the two translations were compared and resulted in an initial compromised translation version which consisted of a consensus of the appropriateness of the items and compromise between the two initial translations. At this stage the collaboration of a team of researchers specialized in research with children with cerebral palsy was requested. These researchers' task was to document their assessments item by item, choose the best translation, and in case neither was adequate, they should suggest another translation. They were instructed to focus on the cultural and linguistic differences that could cause difficulties when the English version was transformed into Brazilian Portuguese.

In the third step, a back translation was understaken, a critical phase to ensure that the content, from the conceptual point of view, had not been modified in the translation ${ }^{26}$. At this time, a native and fluent in English translator was requested to carry out the back-translation, that is, the compromised translation was translated back into English. The back translation was referred to the authors of the original questionnaire CP QOL-Child in order to identify and correct semantic, idiomatic and conceptual discrepancies.

In the fourth step, a review and comparison of the corrected version back-translated by the authors of the questionnaire with the original English version was performed in order to generate the final translation that was used in the following pre-test step.
The final Portuguese version was used with a group of six caregivers of children with cerebral palsy to verify if all items were understandable and satisfactory. The questions that were not easily understood were discussed and redrafted by a panel of researchers and used with another group of six caregivers, to test the cultural equivalence of the instrument until all items were understood by $90 \%$ of interviewees ${ }^{27}$.

After completion of the translation and cultural adaptation process of the instrument, the reliability of the instrument was verified, which meant verifying the precision capability of a measure ${ }^{12}$. If a measuring instrument always presents the same results when applied to structurally equal targets, one may rely on the significance of the measure and regard the measure as reliable 28

The reliability of the CP QOL-Child: primary caregiver questionnaire Brazilian Portuguese version was assessed by means of three interviews.

Inter and intra-observer reliability were checked. The inter-observer reliability was assessed based on measurements taken at the same time by different interviewers and intra-observers through testing and retesting which consisted of filling in the questionnaire twice, with enough time between them to exclude the memory effect, but not too much time to avoid alterations in the child's quality of life ${ }^{12}$. Such procedures were used since, despite the completion of the questionnaire be selfadministered, some study participants were illiterate and it was necessary to read of the instrument items to them.

The internal consistency of the instrument was also checked, which acont verifying whether the measures repeated within the same scale (the various items used to measure the dimension) converged, meaning that they are armed in the same direction. It was checked that the items in each dimension form a coherent whole, which means the approximate internal correlation between items is relatively strong ${ }^{12}$.

The study participants answered the Portuguese version of the instrument CP QOL-Child: questionnaire for caregivers three times conducted by two interviewers: E1 and E2. Interviewer 1 (E1) conducted the first evaluation. After an interval of 30 to 60 minutes, Interviewer 2 (E2) carried out a second assessment. Withim of 14 days after the second assessment, a third assessment was made by Interviewer 1 (E1). Participants also answered a questionnaire containing information about: gender of the child and caregiver; respondent's kinship with the child, age of child and caregiver, the child's level of classification according to the Gross Motor Function Classification System (GMFCS), schooling to of the caregiver.

\section{Statistical Analysis}

A Descriptive Statistical analysis was performed to obtain the demographic factor of the study 
population. The intraclass correlation coefficients (ICC) and Cronbach's alpha were used to evaluate the reliability and internal consistency of the instrument ${ }^{25,29}$. The intraclass correlation coefficient was considered excellent when ICC $>0.75$; satisfactory when $0.4<$ ICC $<0.75$ and poor ICC $<0.4$ 30 and was considered significant at $p<0.05$.

Cronbach's alpha value, for the purpose of comparing groups of individuals, it is recommended reliability measures above $0.5^{28}$.

\section{RESULTS}

Data regarding demographic characteristics of children with cerebral palsy indicate a predominance of male children in GMFCS V (Table 1)

Table 1: Demographic characteristics of children

$\begin{array}{lc}\text { Variable } & \mathbf{N}(\%) \\ \text { Age (years) average } \pm \text { standard deviation } & 87 \pm 33 \\ \text { Gender } & \\ \text { Male } & 19(63) \\ \text { Female } & 11(37) \\ & \\ \text { GMFCS Level } & \\ \text { I } & 10(33) \\ \text { II } & 2(7) \\ \text { III } & 4(13) \\ \text { IV } & 3(10) \\ \text { V } & 11(37)\end{array}$

The reliability of the questionnaire for caregivers CP QOL Child - questionnaire for caregivers was adequate, with Cronbach alpha
Regarding the characteristics of the participants, there was a predominance of female respondents, usually mothers who completed high school (Table 2).

Table 2: Demographic characteristics of participants

$\begin{array}{lc}\text { Varia[ble } & \text { N (\%) } \\ \text { Age (years) (average } \pm \text { standard deviation) } & 34.4 \pm 10.4 \\ & \\ \text { Kinship } & 22(73.3) \\ \text { Grandmother } & 01(3.3) \\ \text { Sister } & 01(3.3) \\ \text { Brother } & 22(73.3) \\ \text { Mother } & 04(13.3) \\ \text { Father } & \\ & \\ \text { Education Level } & 01(3.3) \\ \text { Illiterate } & 07(23.3) \\ \text { Complete Elementary School } & 03(10.0) \\ \text { Incomplete Elementary School } & 15(50.0) \\ \text { Complete High School } & 01(3.3) \\ \text { Incomplete High School } & 03(10.0) \\ \text { Graduate } & \\ & \\ \text { Gender } & 05(17) \\ \text { Male } & 25(83) \\ \text { Female } & \end{array}$

coefficient greater than 0.5 , for all domains for the two evaluators. Only the family and pain domains had values below 0.7 (Table 3 ).

Table 3: Internal consistency of the Brazilian Portuguese version of the CP QOL-Child: questionnaire for caregivers

$\begin{array}{lcc}\text { Domain } & \text { Cronbach's Alpha } & \text { Cronbach's Alpha } \\ \text { Social well-being and acceptance } & \text { E 1 } & 0.748 \\ \text { Functionality } & 0.748 & 0.856 \\ \text { Participation and physical health } & 0.856 & 0.763 \\ \text { Emocional well-being and Self-esteem } & 0.763 & 0.828 \\ \text { Access to services } & 0.828 & 0.858 \\ \text { Pain and disability impact } & 0.835 & 0.669 \\ \text { Family health } & 0.711 & 0.649\end{array}$

The results for intra- and inter-observer reliability for each domain of the Brazilian Portuguese version of CP QOL-Child - questionnaire for caregivers was significant for all domains. Intraobserver reliability was excellent for functionality, participation, access to services and pain (ICC >
$0.75)$ and satisfactory for social well-being, family and emotional well-being $(0.4<$ ICC $<0, .75)$. Inter-observer reliability was excellent for functionality, participation, pain and family (ICC > 0.75 ) and satisfactory for access to services and emotional well-being $(0.4<$ ICC $<0.75)$ (Table 4$)$.

Table 4: Intra- and inter-observer reliability of each domain of the Brazilian Portuguese version of the CP QOL-Child: questionnaire for caregivers assessed by intraclass correlation coefficient

\section{Domain}

Social well-being and acceptance

Functionality

Participation and physical health

Emotional well-being and Self-esteem

Access to services

Pain and disability impact

Family health
Intraclass Correlation Coefficient (ICC) Intra-observer (test-retest) Inter-observer

0.724
0.802
0.770
0.625
0.809
0.779
0.652 0.753

0.899

0.878

0.733

0.498

0.834

0.903 


\section{DISCUSSION}

This study has been able to provide a Brazilian Portuguese version of the questionnaire $\mathrm{CP}$ QOLChild - version for caregivers that is a specific instrument for assessing quality of life of children with cerebral palsy.

The methodology followed $21-24$ expert recommendations to ensure a version of the instrument in Brazilian Portuguese transcribed and properly adjusted to the cultural aspects of the population, but equivalent to the original version in English.

Despite the rigorous criteria established for the demographic aspects of caregivers, in order to ensure the representativeness of the Brazilian population, it has to be highlighted that this study was conducted in a specific region of the country. Brazil is characterized by being a multicultural country with important regional differences that can influence the understanding of the questions and answers given by participants, thus the need for further studies in different regions of the contry ${ }^{31}$.

Psychometric properties of the Brazilian version of the CP QOL-Child will be reliable for assessing the quality of life of children with cerebral palsy aged 4 to 12 years old, through their caregivers' report, as was the original version.

Considering that children with $\mathrm{CP}$ generally may have other associated alterations, such as communication difficulties and cognitive impairment, beyond the limitations of mobility and posture, and consequently are not always able to carry out selfreporting, providing an instrument that can be answered by parents or caregivers seems advantageous. In the assessment process of children with developmental disabilities, whether physical, communicative, cognitive or learning, it is essential to have a report by a representative of the child, because it can provide more information about the health and well-being of these subjects, even if it implies potential risk of increasing the subjectivity of findings ${ }^{15}$. For White-Koning et al. ${ }^{20}$, despite the importance of the self-report, in situations in which children cannot express themselves due to the impact of their disability in functional skills, assessment of quality of life can be made using information obtained from their parents, since they know their children deeply. Soares et al. ${ }^{32}$ expressed the importance of the caregiver for supplementary information about a child, because it is they who know them best.

A study by Waters et al. ${ }^{29}$ on the psychometric properties of the original version of the CP QOL Child: primary caregiver questionnaire found similar results to those presented in this study in the analysis of internal consistency for the domains "pain and impact of disability" and "family health". Waters et al $^{29}$ also found lower values for the Cronbach alpha coefficient for these two domains.
As for the low value obtained in the ICC in test-retest (0.652) for the domain "Family Health", can be justified by the fact that the questioning this directed to financial and physical health, and caregiver work, a situation that may have changed within 14 days, the time required between the first and third assessment, seeing that the inter-observer ICC had a high rate (0.903). The domain Emotional Well-being and Self-Esteem which presented the value 0.625 in the intra-observer assessment also refers to subjective evaluation that can present changes withim short interval of time. However, the value obtained for the domain "Access to services" in the inter-observer assessment may indicate the study participants find it difficult to understand this domain.

Researchers have indicated the need to conduct studies with larger samples on which factors and under which conditions may promote quality of life related to health in children and adolescents with $\mathrm{PC}^{33}$. Researchers have indicated that factors such as accessibility, family aspects ${ }^{34}$, access to rehabilitation and availability of assistive technology resources ${ }^{35}$ interfere or promote the perception of quality of life for individuals with disabilities.

As these children have very peculiar needs and characteristics, it is recommended that the assessment of quality of life be accomplished through specific instruments. Morales ${ }^{36}$, in his study, emphasizes the need to use a specific instrument especially to assess the psychosocial construct, which would provide more obvious contributions on the impact of different CP types on quality of life.

From this perspective, the World Health Organization has recommended the translation and cultural adaptation of existing assessment tools because it facilitates the comparison of data from studies conducted in different countries and the communication among researchers ${ }^{37}$.

Thus, the Brazilian Portuguese version of the CP QOL-Child: questionnaire for primary caregivers can be considered a suitable, reliable and easy to use instrument to assess the quality of life of children with cerebral palsy through their caregivers' reports.

This study also highlights the importance of finalizing the validity process of the instrument through a psychometric analysis of the CP QOLChild: child self-report, as this instrument will provide important additional information regarding the QOL of these individuals.

\section{ACKNOWLEDGEMENTS}

Elizabeth Waters and his team for authorizing the translation and analyzing the psychometric properties of the instrument. The National Council for Scientific and Technological Development (CNPq) for their financial support. Process No. 474184/2009-9. 


\section{REFERENCES}

1. Msall ME, Park Jj Neurodevelopmental Management Strategies for Children With Cerebral Palsy: Optimizing Function, Promoting Participation, and Supporting Families. Clin Obstet Gynecol. 2008; 51 (4): 800-15.

2. O'Shea TM. Diagnosis, Treatment, and Prevention of Cerebral Palsy. Clin Obstet Gynecol. 2008; 51 (4): 816-28.

3. Paneth N. Establishing the Diagnosis of Cerebral Palsy. Clin Obstet Gynecol. 2008; 51 (4): 742-48.

4. Lin, J. P. The cerebral palsies: a physiological approach. J Neurol Neurosurg Psychiatry. 2003; 74 (Suppl 1): 23-9.

5. Reddihough DS, Collins KJ. The epidemiology and causes of cerebral palsy. Aust J Physiother. 2003; 49 (1): 7-12.

6. Shimony JS, Lawrence R, Neil JJ, Inder TE. Imaging for diagnosis and treatment of cerebral palsy. Clin obstet gynecol. 2008; 51(4): 787-99.

7. Lima CLA, Fonseca LF. Paralisia cerebral: neurologia, ortopedia, reabilitação. Rio de Janeiro: Guanabara Koogan; 2004.

8. Surveillance of Cerebral Palsy in Europe. Prevalence and characteristics of children with cerebral palsy in Europe. Dev Med Child Neurol. 2002; 44 (9): 633-640.

9. Bax M, Goldstein M, Rosenbaum P, Leviton L, Paneth N, Dan B, et al. Proposed definition and classification of cerebral palsy, april 2005. Dev Med Child Neurol. 2005; 47 (8): 571-76.

10. Carlon S, Shields N, Yong K, Gilmore R, Sakzewski L, Boyd R. A systematic review of the psychometric properties of Quality of Life measures for school aged children with cerebral palsy. BMC Pediatrics. 2010; 10 (81): 1-11.

11. Vargus-Adams J. Health- related quality of life in childhood cerebral palsy. Arch Phys Med Rehabil. 2005; 86 (5): 940-5.

12. Viehweger $E$, Robitail S, Rohon MA, Jacquemier $M$, Jouve JL, Bollini G, et al. Measuring quality of life in cerebral palsy children. Ann Readapt Med Phys. 2008; 51 (2): 129-137.

13. Calderón-Sepúlveda R F. Escalas de medición de la función motora y la espasticidad en parálisis cerebral. Rev Mex Neuroci. 2002; 3 (5): 285-89.

14. Waters E, Maher E, Salmon L, Reddihough D, Boyd R. Development of a condition-specific measure of quality of life for children with cerebral palsy: empirical thematic data reported by parents and children. Child Care Health Dev. 2005; 31 (2): 127-135.

15. Morales NMO, Funayama CAR, Rangel VO, Frontarolli AC, Araújo RRH, Pinto RMC, et al. Psychometric properties of child health assessment questionnaire (CHAQ) applied to children and adolescents with cerebral palsy. Health and Quality of Life Outcomes. 2008; 6 (109): 1-10.

16. Wallander JL, Schmitt M, Koot HM. Quality of life measurement in Children and Adolescents: Issues, Instruments, and Applications. J Clin Psychol. 2001; 57 (4): 571-585.

17. Dickinson HO, Parkinson KN, Ravens-Sieberer $U$, Thyen U, Arnaud C, Beckung E, et al. Selfreported quality of life of 8-12-year-old children with cerebral palsy: a cross sectional European study. Lancet. 2007; 369 (9580): 2171-78.

18. Liptak G S, O’Donnell M, Conaway M, Chumlea WC, Wolrey G, Henderson RC, et al. Health status of children with moderate to severe cerebral palsy. Dev Med Child Neurol. 2001; 43 (6): 364-70.

19. Livingston $\mathrm{MH}$, Rosenbaum PL, Russell DJ, Palisano RJ. Quality of life among adolescents with cerebral palsy: what does the literature tell us? Dev Med Child Neurol. 2007; 49 (3): 225-31.

20. White-Koning M, Arnaud C, Dickinson HO, Thyen $\mathrm{U}$, Beckung E, Fauconnier J, et al. Determinants of child-parent agreement in Quality-of-life reports: a Europen study of children with cerebral palsy. Pediatrics. 2007; 120 (4): 804-14.

21. Waters E, Davis E, Boyd R, Reddihough D, Mackinnon A, Graham hk, et al. CP QOL-Child Manual. Cerebral Palsy Quality of Life Questionnaire for Children (CP QOL-Child). 2006a. Disponível em: http:// w w w . c pqol.org.au / u ploads/pdfs / cpqol_caregiver_print.pdf > Acesso em: 11 nov. 2008.

22. Guillemin F, Bombardier C, Beaton D. Crosscultural adaptation of healthrelated quality of life measures: literature review and proposed guidelines. J Clin Epidemiol. 1993; 46 (12): 1417-32.

23. Guillemin F. Cross-cultural adaptation and validation of health status measures. Scand J Rheumatol. 1995; 24 (2): 61-3.

24. Melchiors AC, Correr CJ, Fernández-Llimos F. Tradução e Validação para o Português do Medication Regimen Complexity Index. Arq Bras Cardiol. 2007; 89 (4): 210-18.

25. Waters E, Davis E, Boyd R, Reddihough D, Mackinnon A, Graham HK et al. Cerebral palsy quality of life for children translation guidelines. Melbourne: Deakin University; 2006b.

26. Picon P, Gauer GJC, Fachel JMG, Manfro GG. Desenvolvimento da versão em português do Social Phobia and Anxiety Inventory (SPAI). Rev. psiquiatr. 2005; 27 (1): 40-50.

27. Soárez PC, Kowalski CCG, Ferraz MB, Ciconelli RM. Tradução para português brasileiro e validação de um questionário de avaliação de produtividade. Rev Panam Salud Publica. 2007; 22 (1): 21-8. 
28. Maroco J, Garcia-Marques T. Qual a fiabilidade do alfa de Cronbach? Questões antigas e soluções modernas? Laboratório de Psicologia. 2006; 4 (1): 65-90.

29. Waters E, Davis E, Mackinnon A, Boyd R, Graham HK, Kai LoS, et al. Psychometric properties of the quality of life questionnaire for children with CP. Dev Med Child Neurol. 2007; 49 (1): 49-55.

30. Szklo R, Nieto FJ. Epidemiology Beyond the Basis. Burlington: Jones \& Bartlett Learning; 2008.

31. Guedes DP, Guedes JERP. Tradução, adaptação transcultural e propriedades psicométricas do KIDSCREEN-52 para a população brasileira. Rev Paul Pediatr. 2011; 29 (3): 364-371.

32. Soares E, Serrano A, Guralnick MJ.Translation, adaptation and content validation of section I of the scale "assessment of peer relations" into the portuguese language. Journal of Human Growth and Development. 2012; 23(1): 31-40.

33. Frontini R, Crespo C, Carona C, Canavarro MC. Health-Related Quality of Life and its Correlates in Children with Cerebral Palsy: An Exploratory Study. J Dev Phys Disabil. 2011; 24 (2): 181-196

34. Interdonato GC, Greguol M. Rev Bras Crescimento Desenvolvimento Hum. 2011; 21(2): 282-295

35. Braccialli LMP, Rebelo F, Pereira L. Can Virtual Reality Methodologies Improvethe Quality of Life of People with Disabilities? In: Rebelo F, Soares, MM. (Org.). 1st ed. Advances in Usability Evaluation. Boca Raton: CRC Press; 2012. p. 40-60.

36. Morales NMO. Avaliação Transversal da Qualidade de Vida em Crianças com Paralisia Cerebral por Meio de um Instrumento Genérico (CHQ-PF50) [Dissertação]. Uberlândia: Faculdade de Medicina da Universidade Federal de Uberlândia; 2005.

37. World Health Organization. The World Health Organization Quality of Life Assessment (WHOQOL): position paper from THE WORLD HEALTH ORGANIZATION. SOC Sci Med. 1995;41(10):1403-9. 